\title{
Investigating the Performance of a Laboratory Dynamometer for a Three-wheeler Engine Test Rig
}

\author{
${ }^{* 1}$ Oluwaseun K. Ajayi, ${ }^{2}$ Oluleke Oluwole, ${ }^{1}$ Adebayo A. Fadairo, ${ }^{2}$ Nosa Idusuyi, \\ ${ }^{3,4}$ Abiola J. Adeyi and ${ }^{5}$ Ezekiel B. Omoniyi \\ ${ }^{1}$ Department of Mechanical Engineering, Obafemi Awolowo University, Ile-Ife, Nigeria \\ ${ }^{2}$ Department of Mechanical Engineering, University of Ibadan, Nigeria \\ ${ }^{3}$ Forestry Reserve Institute of Nigeria, Ibadan, Nigeria \\ ${ }^{4}$ Department of Mechanical Engineering, Ladoke Akintola University of Technology, Ogbomoso, Nigeria \\ ${ }^{5}$ Department of Mechanical Engineering, Bells University, Ota, Nigeria \\ \{okajayi | afadairo\}@oauife.edu.ng | \{ooluwole I nidusuyi\}@gmail.com | adeyi.abiola@yahoo.com | omofowowe@gmail.com
}

Received: 14-SEP-2021; Reviewed: 29-SEP-2021; Accepted: 29-SEP-2021

http://dx.doi.org/10.46792/fuoyejet.v6i3.696

\begin{abstract}
The dynamometer is to mimics driving condition in an indoor controlled condition measuring engine output parameters like speed, torque, power, combustion conditions and exhaust compositions. However, the complexity and dynamics involved in the making of this instrument makes it unaffordable for student research except it is funded. This work reports an innovative method adopted to measure a three-wheeler engine output parameters. An automobile vehicle dynamo was adopted which requires low speed and outputs high torque. Driving conditions were incorporated as brakes for the dynamo which mimics the driving terrains experienced by the engine. A data acquisition unit capable of converting the electrical signals into readable values on a screen and a user interface on a PC completed the dynamometer development. The dynamometer was then calibrated against known output values of speed and torque. A three-wheeler engine was mounted on a test rig and the dynamometer was used to measure output speed, torque and energy dissipated. A Bajaj engine was mounted and the engine output tested for two types of transmission of manual and continuously variable transmission. The measured output from the engine showed that the developed dynamometer performed effectively and therefore be adopted for use for student research in this area.
\end{abstract}

Keywords- dynamometer, load, speed, terrain, torque.

\section{INTRODUCTION}

T he dynamometer is the most important measuring device in measuring engine output parameters because it combines various functions like speed measurement, torque measurement, power measurement, exhaust temperature measurement among others. Direct methods usually make use of brakes for measuring speed and torque simultaneously, while the indirect method uses approximate means (Chybowski, 2008).

Over the years, dynamometer have been applied for several applications as follows; A fractional horsepower dynamometer is used in Mechatronics, non-linear and adaptive control laboratory experiments (fractional horsepower), a rope brake dynamometer coupled with brake and motor to measure the minimum torque and various factors involved while the design is done (Gopinath 2014), Kin-Con dynamometer and an external recording system for Force, angle and velocity from the Kin-Con dynamometer against known weights, angles and user velocities (performance kin-con), bulb dynamometer to synthesise children with their weight, height, body composition and handedness (de Souza et al. 2014), and in another application, a chassis dynamometer was used to describe and refine the European Driving Cycle (EDC) (Casadei \& Maggioni 2016).

\section{${ }^{*}$ Corresponding Author}

Section C- MECHANICAL ENGINEERING \& RELATED PHYSICAL SCIENCES Can be cited as:

Ajayi O., Oluwole O., Fadairo A., Idusuyi N., Adeyi A.J. and Omoniyi E.B. (2021): Investigating the Performance of a Laboratory Dynamometer for a Three-wheeler Engine Test Rig, FUOYE Journal of Engineering and Technology (FUOYEJET), 6(3), 43-46. http://dx.doi.org/10.46792/fuoyejet.v6i3.694
More recent reports on dynamometer includes; dynamometer use based on direct torque control for motorized spindles (Tongtong et al., 2019), determination of the performance of interventions in trunk flexors (Rodriguez-Perea et al., 2019), aircraft landing gear wheel force and moment determination (Jaroslaw et al., 2020), laboratory testing for a fuel cell vehicle (Loshe-Busch et al., 2020), comparison of data obtained from dynamometer with pin-on-disc (Federici et al., 2019), influence of load, fuel, driving conditions and resistance conditions on heavy diesel vehicles (Chen et al., 2018) and brake wear emission measurement (Mathissen et al., 2019). The experience of drivers and users of threewheelers is an important which can be described through the driving patterns based on users need (Bagul et al., 2021). Studies are continuously ongoing on driver behaviour (Adisa and Eludiora, 2021) and driving patterns (Bagul et al., 2021) for small engines but the equipment to effectively carry this out are very expensive, hence the need to locally develop methods of solving this issue. This study was carried out to develop a dynamometer using available resources locally for student research in engine performance testing.

\section{Methodology}

This session explains the materials, method and testing of the dynamometer.

\subsection{MATERIALS}

\subsubsection{Microcontroller}

Various factors are considered in the choice of microcontroller to be used for a particular purpose. These include: the number of digital inputs, analogue inputs and size of program memory storage required, the magnitude of clock frequency, the number of interrupts and timer circuits required and an internal ADC stage. 


\subsubsection{Data Acquisition Unit}

The components used in building the Data Acquisition Unit of the dynamometer are resistors, capacitors, diode, bridge rectifier, transistor (Bipolar junction transistor), transformer (step-down), LCD, crystal oscillator and current sensor.

\subsubsection{The Power Supply Configurations}

A $+5 \mathrm{~V}$ direct current (DC) supply was used across the components except the relays which was at $12 \mathrm{~V}$. The power supply has a linear power supply consisting of step-down transformer, filter capacitor, and voltage regulators to give the various voltage levels. The power supply circuit diagram is shown in figure 1. A rectifier was developed with four diodes to form a full wave bridge network. Also, from figure $1, C_{1}$ is the filter capacitor which is inversely proportional to the ripple gradient of the power supply, when arranged with a $240 \mathrm{~V}$ transformer on a $50 \mathrm{~Hz}$ supply. The transformer secondary gave r.m.s voltage output of $12 \mathrm{~V}$.

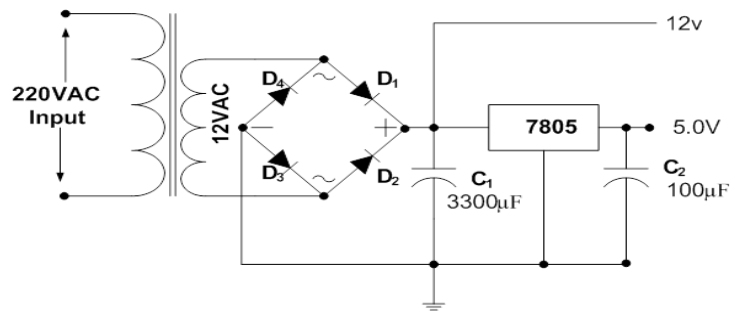

Fig. 1: Power supply circuit

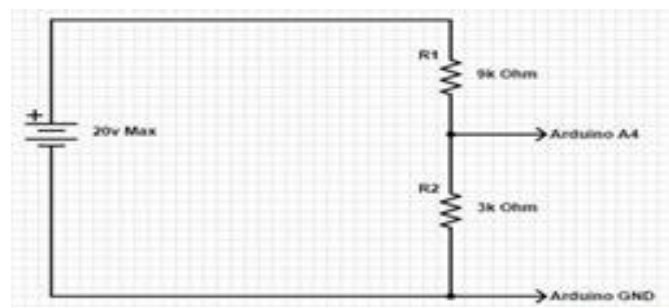

Fig. 2: Voltage Divider

\subsubsection{Voltage Divider And Current Monitoring Stage}

The Arduino can only accept voltage up to $5 \mathrm{v}$ on an analogue input. However, voltage across a circuit can range as high as $20 \mathrm{vdc}$ in certain situations especially in an open circuit pv voltage. At such instances, a voltage divider that would provide $5 \mathrm{~V}$ at $20 \mathrm{~V}$ battery voltage and less at according to requirement of various components was designed for this work. In other to achieve the voltage level across the components, a voltage divider calculator shown in figure 2 was used. The parameters were set that $20 \mathrm{~V}$. The next step is to track the current being consumed by a load, or produced by a source. ACS715 Hall Effect sensor was used to track the current being passed.

\subsection{CONSTRUCTION}

After carrying out all design and analysis, the project was constructed and tested to ensure its working ability. The construction was done in three different stages.

1 . The implementation of the whole project on a solderless experiment board (bread board).

2. The soldering of the circuits on Vero-boards.

3 . The coupling of the entire project to the casing.

\subsection{BRAKING - TERRAIN MIMIC}

The braking system is a set of resistors arranged in parallel with switch for each one so that they work independently. They are made of automobile head lamp bulbs with two types of capacities; $120 \mathrm{~W}$ and $800 \mathrm{~W}$ combined to form; $120 \mathrm{~W}, 800 \mathrm{~W}, 920 \mathrm{~W}$ and $1600 \mathrm{~W}$ representing $\mathrm{L}_{0}, \mathrm{~L}_{1}, \mathrm{~L}_{2}$, $\mathrm{L}_{3}$ and $\mathrm{L}_{4}$ respectively.

The other parts that make up the dynamometer are; Switches (2 types: single pole, single throw and double pole, single throw), USB Jack capable: for data transfer, A DC motor (Bosch for Benz cars), A 12V 60mAh DC Battery, capacitor, Arduino software and Laptop.

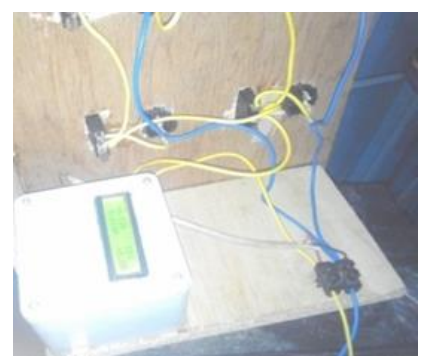

Fig. 3: Data Acquisition Unit
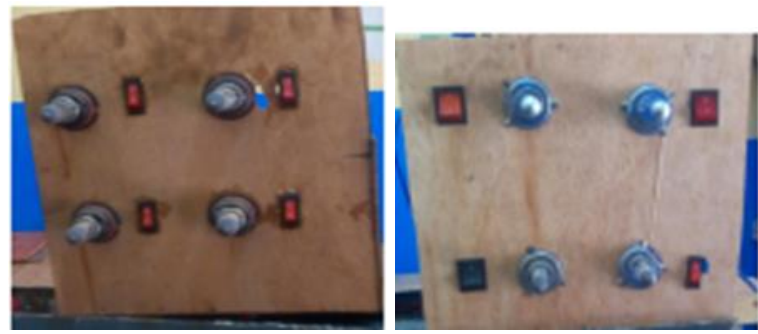

Fig. 4: (a) $120 \mathrm{~W}$ and (b) 800W load board

\section{Results And Discussion}

The data recorded for speed and torque for CVT and manual transmission are presented in figures 5 and 6 respectively.

A Bajaj three-wheeler engine was mounted on its test rig while the dynamometer was also connected to the engine and test rig to record the speed and torque output of the engine. The engine was run first when there was no load or braking on the dynamometer and data was recorded for both manual transmission (MT) and continuously variable transmission (CVT) respectively. The engine was run throughout its entire transmission ratio for both transmission type and the data recorded are presented in Tables $1 \& 2$. Subsequently, the data were analysed at 95.5\% confidence level as presented in Tables $3 \& 4$ showing the mean, variance and confidence level. 
Table 3. ANOVA for Speed (MT vs CVT)

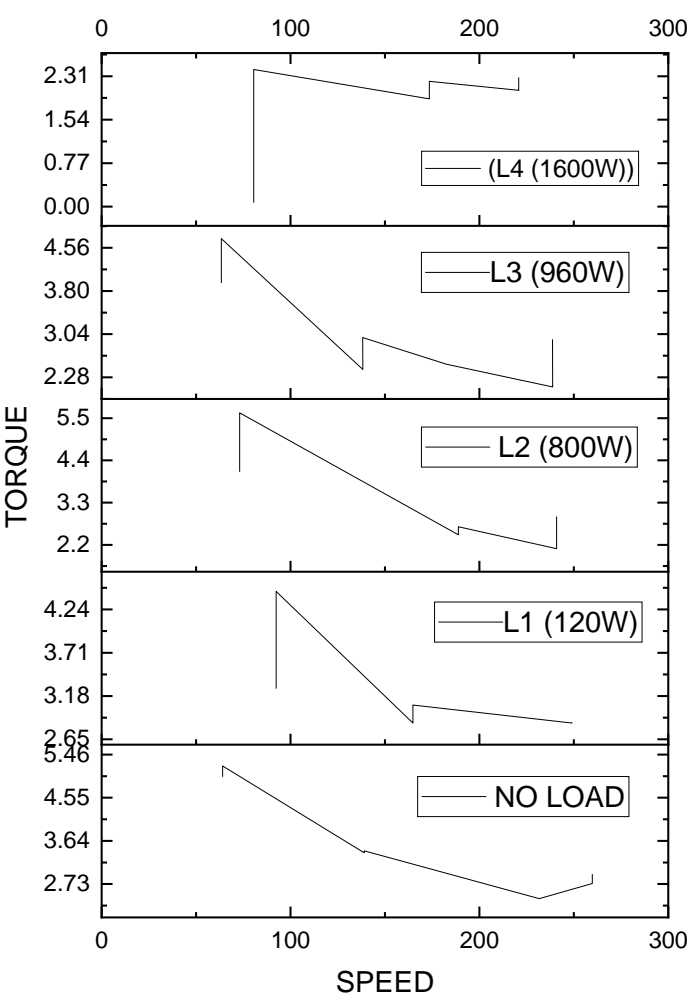

Fig. 5: Result of CVT Transmission using the dynamometer from No load to $L 4$

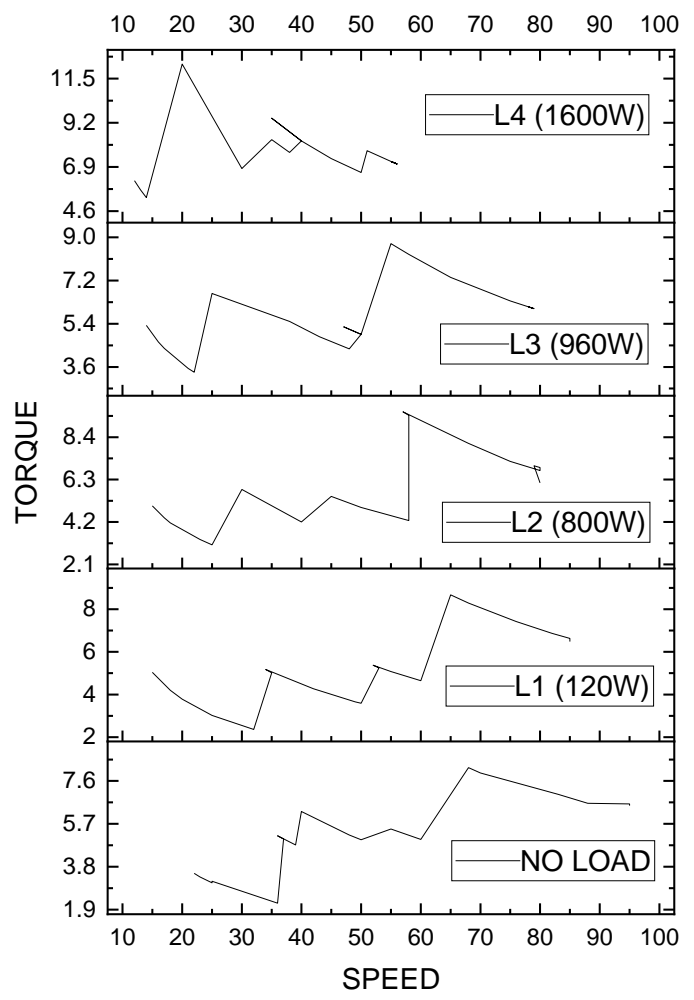

Fig. 6: Result of Manual Transmission using the dynamometer from No load to L4

\begin{tabular}{|c|l|l|l|l|r|r|}
\hline \multirow{2}{*}{ SPEED } & \multicolumn{2}{|c|}{ Mean } & \multicolumn{2}{c|}{ Variance } & F & F critical \\
\cline { 2 - 7 } & MT & CVT & MT & CVT & & \\
\hline Lo & 54.96 & 177.15 & 530.77 & 7423 & 40.383 & 4.183 \\
\hline L1 & 53.74 & 169.22 & 537.93 & 5259.14 & 47.186 & 4.183 \\
\hline L2 & 53.09 & 164.97 & 524.17 & 6253.99 & 38.953 & 4.183 \\
\hline L3 & 51.09 & 162.75 & 543.63 & 5526.63 & 42.376 & 4.183 \\
\hline L4 & 40.74 & 167.22 & 268.93 & 3959.14 & 81.021 & 4.196 \\
\hline
\end{tabular}

Table 4: ANOVA for Torque (MT vs CVT)

\begin{tabular}{|c|l|l|l|l|l|l|}
\hline \multirow{2}{*}{ TORQUE } & \multicolumn{2}{|c|}{ Mean } & \multicolumn{2}{c|}{ Variance } & \multicolumn{1}{|c|}{ F } & F critical \\
\cline { 2 - 7 } & MT & CVT & MT & CVT & & \\
\hline Lo & 5.61 & 3.51 & 3.19 & 1.08 & 9.77 & 4.183 \\
\hline L1 & 5.51 & 3.21 & 3.13 & 0.31 & 12.75 & 4.183 \\
\hline L2 & 5.79 & 3.37 & 3.21 & 1.36 & 12.64 & 4.183 \\
\hline L3 & 5.78 & 3.07 & 2.01 & 0.74 & 25.73 & 4.183 \\
\hline L4 & 7.37 & 1.86 & 1.98 & 0.66 & 95.87 & 4.196 \\
\hline
\end{tabular}

From the analysis, it can be seen that there was significant difference in the data for each loading condition for each of the transmissions type. In line with the relationship between speed and torque, the result correlates with the inverse relationship between speed and torque. Also, the values recorded for speed and torque were higher for the CVT than in MT, depicting a better performance of the CVT over the MT.

\section{Conclusions And Recommendations}

The test carried out using the developed dynamometer was repeated three times and the same result was recorded for each. The indication of this is that the dynamometer performance is acceptable for the intended use for student research work. The variations recorded in the readings for various conditions and transmissions for speed and torque accurately compare with known relationships for these parameters. Also, the components used for braking or otherwise driving terrain mimic were adequate and it is sufficient to describe the three-wheeler drive cycle. The variations are significant at $95.5 \%$ confidence level and the design and experiment can be replicated.

\section{REFERENCES}

Adisa A. O. and Eludiora S. I. (2021). An improved vehicle registration and licensing system. FUOYE Journal of Engineering and Technology, 6(1), 21-25.

Bagul T. R., Kumar R. and Kumar R. (2021). Real-world emission and impact of three wheeler electric auto-rickshaw in India. Environmental Science and Pollution Research, https://doi.org/10.1007/s11356-021-14805-6.

Casadei, S. and Maggioni, A., (2016). Performance testing of a Locomotive Engine after treatment Pre-prototype in a Passenger Cars Chassis Dynamometer Laboratory. Transportation Research Procedia, 14, 605-614.

Chen, L., Wang, Z., Liu, S. and Qu, L. (2018). Using a chassis dynamometer to determine the influencing factors for the emissions of Euro VI vehicles. Transport and Environment, 65, 564573.

Chybowski, L. (2008). Assessment of marine engines torque load without using of the torquemeter. Journal of Polish CIMAC, Gdansk University of Technology, Poland. 
De Souza, M.A., de Jesus ALves, B., Rogan, C., Baranauskes, B., Mataruco, M., Pizzeto, T.M. and Mattiello-Sverzut, A.C. (2014). Normative data for hand grip strength in healthy children measured with a bulb dynamometer: A cross-sectional study. Physiotherapy (United Kingdom), 100(4), .313-318.

Federici, M., Alemani, M., Menapace, C., Gialanella, S., Perricone, G. and Straffelini, G. (2019). A critical comparison of dynamometer data with pin-on-disc data for the same two fraction material pairs- A case study. Wear, 424-425, 40-47.

Gopinath, R., (2014). Design of a rope brake dynamometer. Middle East Journal of Scientific Research, 20(5), 650-655.

Jaroslaw, P., Piotr, B., Tomasz, L., Jerzy, J., Joanna, M., Arkadiusz, T., Dariusz, B. and Jan, L. (2020). Determining wheel forces and moments on aircraft landing gear with dynamometer sensors. Sensors, 20(1), 227.

Lohse-Busch, H., Stutenberg, K., Duoba, M., Liu, X., Elgowainy, A., Wang, M., Wallner, T., Richard, B. and Christenson, M. (2020). Automotive fuel cell stack and system efficiency and fuel consumption based on vehicle testing on chassis dynamometer at minus $18{ }^{\circ} \mathrm{C}$ to positive $35^{\circ} \mathrm{C}$ temperatures. International Journal of Hydrogen Energy, 45(1), 861-872.

Mathissen, M., Grigoratos, T., Lahde, T. and Vogt, R. (2019). Brake wear particle emissions of a passenger car measured on a chassis dynamometer. Atmosphere, 10(9), 556.

Rodriguez-Perea, A., Chirosa Rios, L. J., Martinez-Garcia, D., UlloaDiaz, D., Rojas, F. G., Jerez-Mayorga, D. and Chirosa Rios, I. J. (2019). Reliability of isometric and isokinetic trunk flexor strength using a functional electromechanical dynamometer. Peer J: e7883, https://doi.org/10.7717/peerj.7883.

Tarte, Y. and Chen, Y., (2006). Fractional horsepower dynamometera general purpose hardware-in-the-loop real-time simulation platform for nonlinear control research and education. 45th IEEE Conference on Control, 3912-3917. Available at: http://ieeexplore.ieee.org/xpls/abs all.jsp?arnumber=4177998.

Tongtong, J., Chuanhai, C., Qion,g w., Zhaojun, Y., Jun, Y. and Shizhang, L. (2019). Research on the dynamometer system for double motorized spindles. Advances In Mechanical Engineering, $1(14), 1-16$ 